\title{
Correction to: Review of brain encoding and decoding mechanisms for EEG-based brain-computer interface
}

\author{
Lichao $\mathrm{Xu}^{1}(\mathbb{D}) \cdot$ Minpeng $\mathrm{Xu}^{1,2} \cdot$ Tzyy-Ping Jung ${ }^{1,2,3} \cdot$ Dong Ming ${ }^{1,2}$
}

Published online: 5 June 2021

(C) Springer Nature B.V. 2021

Correction to: Cognitive Neurodynamics

https://doi.org/10.1007/s11571-021-09676-z

In the original publication of the article, the 3rd author name was incorrectly published as "Tzzy-Ping Jung".

The correct name of the author is "Tzyy-Ping Jung".
The original article has been corrected.

Publisher's Note Springer Nature remains neutral with regard to jurisdictional claims in published maps and institutional affiliations.

The original article can be found online at https://

doi.org/10.1007/s11571-021-09676-z.

Dong Ming

richardming@tju.edu.cn

1 Academy of Medical Engineering and Translational Medicine, Tianjin University, Tianjin, China

2 Department of Biomedical Engineering, College of Precision Instruments and Optoelectronics Engineering, Tianjin University, Tianjin, China

3 Swartz Center for Computational Neuroscience, University of California, San Diego, USA 